\title{
A Survey Based Study for the Assessment of Knowledge and Practice of Community Pharmacy Personnel on Good Pharmacy Practice in Hyderabad, India.
}

\author{
Anup Jagarlamudi", Asma Begum, Mahalakshmi Teegala \\ Department of Clinical Pharmacy Practice, Pullareddy Institute of Pharmacy, Hyderabad, Telangana, INDIA.
}

\begin{abstract}
It has been more than two decades since the Good pharmacy practice guidelines were framed by WHO-FIP jointly and also The IPA had also framed the Good pharmacy practice guidelines 16 years back. The main objective behind the guidelines was to improve the quality of services provided by the community pharmacists and also to promote that the health of the patient is also the responsibility of these pharmacists.

Nowadays the focus is on patient-centered Medication therapy and hence in our study we have tried to assess the knowledge and practice of community pharmacy personnel toward Good pharmacy practice guidelines in Hyderabad. We have developed a survey form consisting of 44 questions based on the WHO-FIP guidelines and also on the basis of IPA guidelines. A total of 500 survey forms were distributed at various community pharmacies covering all the areas of Hyderabad.

We have received 302 filled in survey forms and these were analyzed question wise and the results obtained were disappointing. $43.3 \%$ of dispensing pharmacists were from a different educational background and $15.8 \%$ personnel were holders of $10+2$ certificate and $3.97 \%$ were holders of 10 th class certificate. The maximum number of days of training received were 180 days and the minimum number of days of training received were 0 days. Majority of dispensing pharmacists were aware of medication errors and when questioned about the action taken by them if they encountered a prescription with medication errors, surprisingly all of them answered that they will overlook such errors and again when asked why they were overlooking these errors, they have answered that they cannot question the doctors.

The authorities must be extra vigilant while licensing a pharmacy and also should be inspecting these pharmacies frequently and also more educational reforms must be inculcated both at the institutional level and also at the practicing level. The practicing pharmacists must be encouraged to attend continuous educational and knowledge upgrading programmes.
\end{abstract}

Key words: Community pharmacists, Dispensing pharmacists, Hyderabad, Good pharmacy Practice.

\section{INTRODUCTION}

The health of the public is fundamental to the happiness and welfare of all people. Barriers to good health include poor access to quality medical products, poor access to trained health professionals and care, inadequate health workforce, unaffordable cost of healthcare and poor standards of health care professionals education. Medicines are an essential and critical part of health-care services in all cultures and societies. When accessed, medicines are often used as an essential component of many disease prevention programmes and virtually all disease treatment plans. The
DOI: 10.5530/ijopp.11.1.4

Address for correspondence: Mr. Anup Jagarlamudi M.Pharm, (Ph.D),

Associate Professor,Department of Clinical Pharmacy Practice, Pullareddy Institue of Pharmacy, Domadugu village, Near Annaram Air Force Academy, Jinnaram Mandal, Sangareddy District, Telengana -502313, INDIA. Phone no: 91-7382670545 Email Id: anupjagarlamudi@ gmail.com

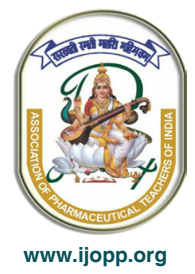


potential benefit of medicines is often not realized - there is a gap between the proven efficacy of medicines demonstrated in clinical trials and their actual effectiveness in practice. The reasons for this gap include problems with drug selection and dosages, improper administration of medicines and lack of adherence by patients to prescribed treatment, drug-drug and drug food interactions, and adverse drug events. Besides clinical problems associated with drug-related problems, there are cost implications. It has been estimated that the cost of problems with the use of medicines is equal to or greater than the cost of the medicines themselves. Pharmacists are specifically educated and trained health professionals who are charged by their national or appropriate (e.g. state or provincial) authorities with the management of the distribution of medicines to consumers and to engage in appropriate efforts to assure their safe and efficacious use. There is also an increasing recognition that providing consumers with medicines alone is not sufficient to achieve the treatment goals. To address these medication-related needs, pharmacists are accepting greater responsibility for medicines-use outcomes and evolving their practices to provide patients with enhanced medicines-use services. ${ }^{1}$

All practicing pharmacists are obliged to ensure that the service they provide to every patient is of appropriate quality. Good Pharmacy Practice is a means of clarifying and meeting that obligation. ${ }^{2}$

As health-care professionals, pharmacists play an important role in improving access to health care and in closing the gap between the potential benefit of medicines and the actual value realized and should be part of any comprehensive health system. In addition, the increasingly complex and diverse nature of pharmacists' roles in the health-care system and public health demands a continuous maintenance of the competence of pharmacists as health-care professionals who have up-to-date skills and expertise. ${ }^{3}$

GPP or Good Pharmacy Practice may be defined as the practice of pharmacy that responds to the needs of the people who use the service of the pharmacist of providing optimal, evidence-based care. ${ }^{4}$

The mission of pharmacy practice is to provide medications and other health care products and services and to help people and society to make the best use of them. Comprehensive pharmacy service encompasses involvement in activities to secure good health and the avoidance of ill health in the population. When the treatment of ill health is necessary the quality of each person's medicine use process should be assured to achieve maximum therapeutic benefit and to avoid untoward side effects. This presupposes the acceptance by pharmacists of shared responsibility with other professionals and with patients for the outcome of therapy. In recent years the term Pharmaceutical Care has established itself as a philosophy of practice with the patient and the community, as the primary beneficiary of the pharmacist's actions. The concept becomes particularly relevant to special groups of populations such as the elderly, mothers and children, and chronically ill patients, and to the community as a whole, e.g. in terms of cost containment. While the basic concepts of Pharmacentical Care and Good Pharmacy Practice are largely identical, it could be said that Good Pharmacy Practice is the way to implement Pharmaceutical Care. ${ }^{5}$

The pharmacist must be able to use the evidence base (e.g., scientific, pharmacy practice, health system) effectively in order to advise on the rational use of medicines in the health care team. By sharing and documenting experiences, the pharmacist can also contribute to the evidence base with the goal of optimizing patient care and outcomes. As a researcher, the pharmacist must be able to increase the accessibility of unbiased health and medicines-related information to the public and other health care professionals. ${ }^{6}$

Pharmacists should keep themselves updated about the developments in their profession. They should possess excellent communication skills to be able to work closely with other healthcare providers and mutually share the learning.

Pharmacists must maintain healthy relationship with other health care professionals.

In case of any discrepancy / doubt in the prescription, the Pharmacist should contact the doctor over the telephone without unduly alarming the patient, and in a friendly manner, put forward the query to the doctor.

Before doing so, he must doubly check and ensure that there is really an error or discrepancy in the prescription, and also work out the alternative / solution which can be promptly suggested on inquiry from the doctor.

Up-gradation of professional skills and improved understanding between various healthcare professionals in the locality can be achieved through professional interactions. $^{\text {? }}$

To assure quality, pharmacists must know the guidelines and recommendations regarding best practices for survey research and be mindful of the rigour that must be 
applied in the design, conduct and reporting of survey research so that the findings credibly reflect the target population and are a true contribution to the scientific literature. ${ }^{8}$

\section{MATERIALS AND METHODS}

We have planned for a survey across different community pharmacies across all of Hyderabad, and the study was approved by the Institutional review board.

Study Design: Cross-sectional Study.

Study Site: Different community pharmacies across Hyderabad.

Study Duration: 4 months.

Source of Data: A survey form was developed based on WHO-FIP and also on IPA GPP guidelines.

\section{Sample Size: 302.}

Study Procedure: 500 survey forms were distributed at different community pharmacies across all the areas of Hyderabad and the dispensing pharmacists were requested to fill the forms and we have received 302 filled in survey forms. These filled in forms were analysed for results.

Statistical analysis: Descriptive statistical analysis has been carried out in the present study where ever necessary.

\section{RESULTS}

The received filled in Survey forms are analysed question by question.

Question 1 is concerned with the Education qualification of the community pharmacists. The results obtained were as follows:

\begin{tabular}{ccc}
\hline Education & No. Of Personnel & $\%$ of Personnel \\
\hline Diploma & 29 & $9.6 \%$ \\
B.Pharm & 58 & $19.2 \%$ \\
M.Pharm & 23 & $7.61 \%$ \\
$10+2$ & 48 & $15.8 \%$ \\
10 th & 12 & $3.97 \%$ \\
Degree (ordinary) & 131 & $43.3 \%$ \\
Pharm D & 1 & $0.33 \%$ \\
\hline
\end{tabular}

Question 2 is concerned with year of obtaining the

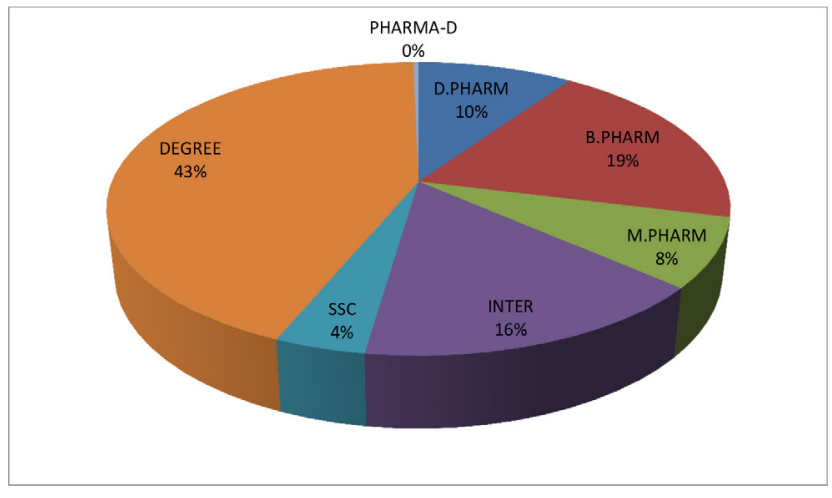

Figure 1: The Education qualification of dispensing pharmacists.

pharmacist registration certificate.

Question 3 is concerned with the duration of training:

We have received different answers from all the responding dispensing pharmacists. In fact the duration of training ranged from days to months, the results of which are as follows:

\begin{tabular}{cc}
\hline Parameter & Value \\
\hline No. of personnel & 302 \\
Minimum No. of days of training & 0 days \\
Maximum No. of days of training & 180 days \\
Mean & 41.6457 \\
Standard Deviation & \pm 51.3630 \\
Variance & 2574.8016 \\
Median & 30 \\
\hline
\end{tabular}

Question 4 is about the total experience as community Pharmacist, and the results obtained were as follows:

\begin{tabular}{cc}
\hline Parameter & Value \\
\hline No. of personnel & 302 \\
Minimum No. of years of experience & 0.1 years \\
Maximum No. of years of experience & 60 years \\
Mean & 7.4493 \\
Standard Deviation & 8.6462 \\
Variance & 74.7568 \\
Median & 4.0000 \\
\hline
\end{tabular}

Question 5 is about experience in that community pharmacy.

Question 6 is about position of pharmacist in pharmacy, and the results obtained as follows:

\begin{tabular}{ccc}
\hline Position & No. Of personnel & Percentage \\
\hline Owners & 73 & 24.17 \\
Employees & 229 & 75.82 \\
\hline
\end{tabular}

Indian Journal of Pharmacy Practice, Vol 11, Issue 1, Jan-Mar, 2018 


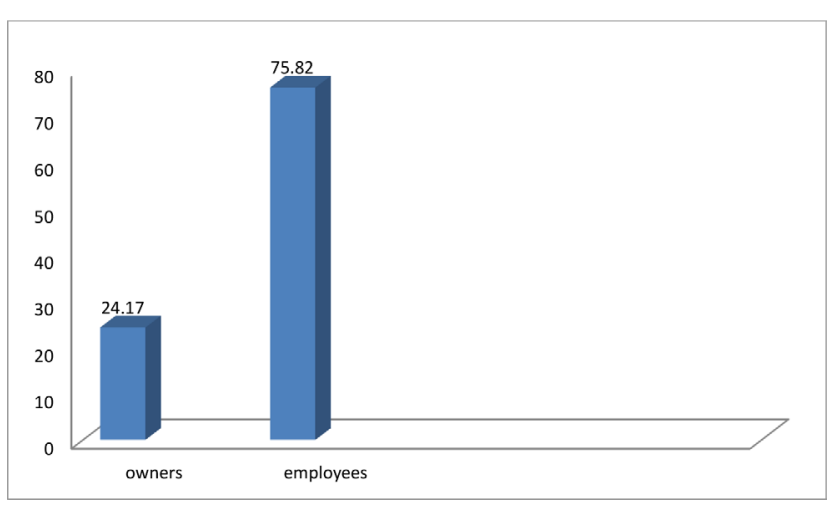

Figure 2: The position of Pharmacist at the Pharmacy.

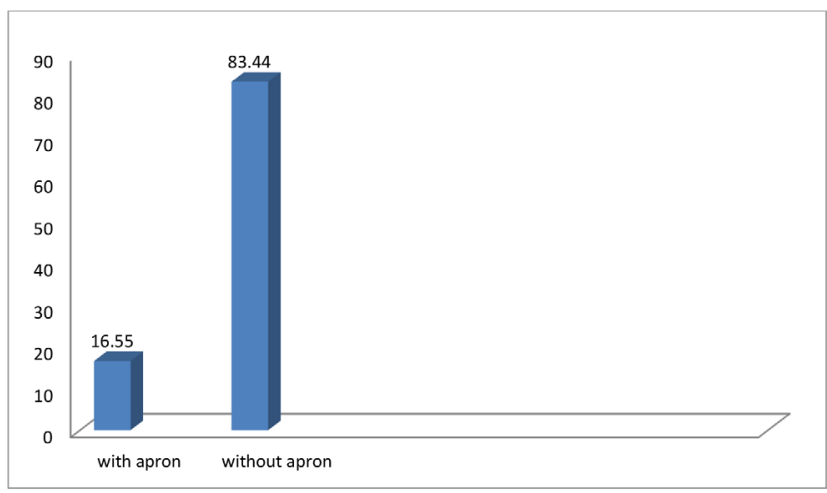

Figure 3: The appearance of Pharmacist.

Question 7 is about the appearance of pharmacist while dispensing, and the results obtained are as follows:

\begin{tabular}{ccc}
\hline Appearance & No. of personnel & Percentage \\
\hline With apron & 50 & 16.55 \\
Without apron & 252 & 83.44 \\
\hline
\end{tabular}

Question 8 is about the procurement of the drugs, and the results obtained are as follows:

\begin{tabular}{ccc}
\hline Procurement method & No. of personnel & Percentage \\
\hline VED & 300 & 99.33 \\
ABC & 2 & 0.66 \\
\hline
\end{tabular}

Question 9 is about arrangement of the drugs in pharmacy, and the results obtained are as follows:

\begin{tabular}{ccc}
\hline Arrangement & No. of personnel & Percentage \\
\hline Alphabetical & 274 & 90.72 \\
Company wise & 21 & 6.9 \\
Therapeutic category & 4 & 1.32 \\
Chronological & 1 & 0.33 \\
Fast or slow moving & 1 & 0.33 \\
None & 1 & 0.33 \\
\hline
\end{tabular}

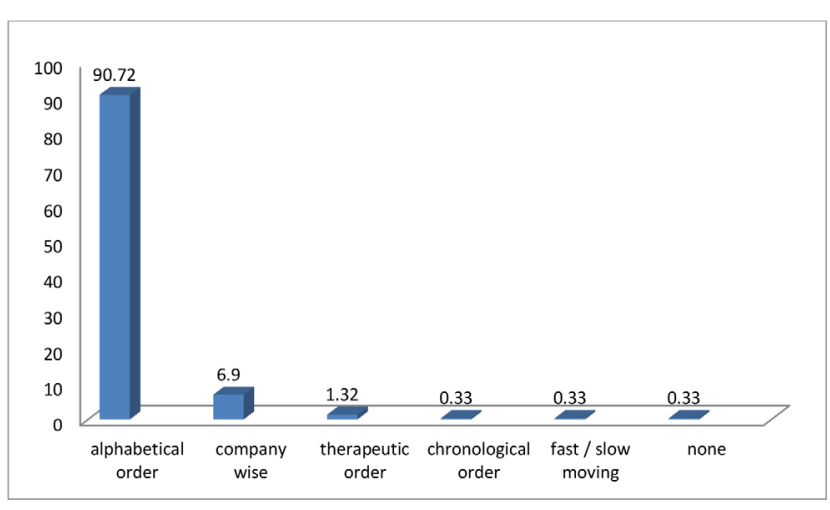

Figure 4: The arrangement of Medicines at the Pharmacy.

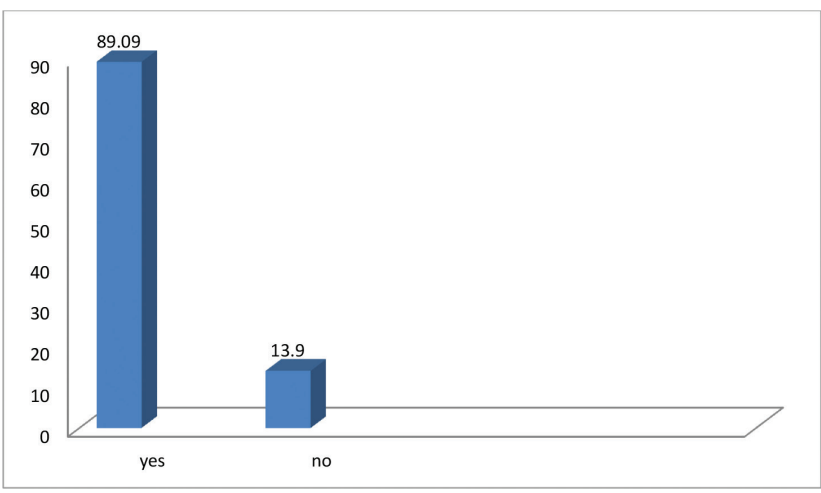

Figure 5: The knowledge of cold chain process.

Question10 is about insulin storage conditions in pharmacy, and the results obtained are as follows:

\begin{tabular}{ccc}
\hline Temperature & No. of personnel & Percentage \\
\hline $2-8^{\circ} \mathrm{C}$ & 298 & 98.67 \\
$<2^{\circ} \mathrm{C}$ & 4 & 1.32 \\
\hline
\end{tabular}

Question 11 is about the cold chain storage process for storage of vaccines, and the results obtained are as follows:

\begin{tabular}{ccc}
\hline $\begin{array}{c}\text { Follows Cold chain } \\
\text { process }\end{array}$ & No. of personnel & Percentage \\
\hline Yes & 260 & 86.09 \\
No & 42 & 13.90 \\
\hline
\end{tabular}

Question 12 is about the responsibility of pharmacist for safety evaluation of prescription, and the results obtained are as follows:

\begin{tabular}{ccc}
\hline Safety evaluation & No. of personnel & Percentage \\
\hline Yes & 282 & 93.37 \\
No & 20 & 6.62 \\
\hline
\end{tabular}

Question 13-18 is about identification of any medical or drug related problem, and the results obtained are as follows: 


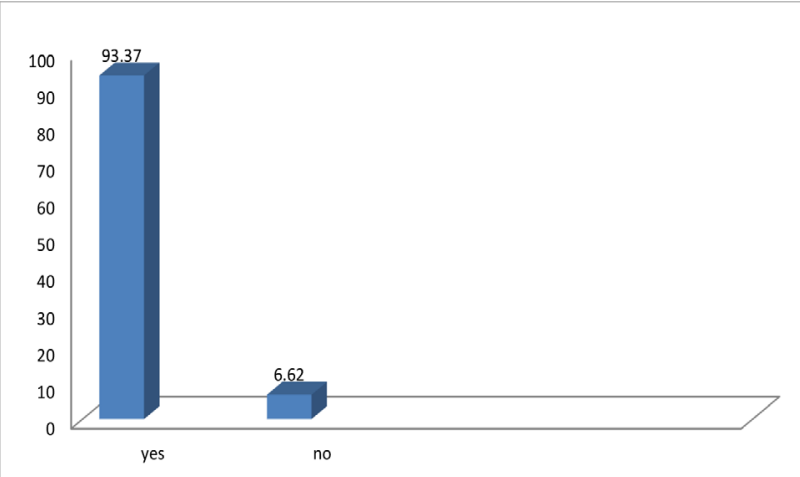

Figure 6: The responsibility of Safety evaluation of Prescription.

\begin{tabular}{cccc}
\hline $\begin{array}{c}\text { Drug/medical } \\
\text { related problem }\end{array}$ & $\begin{array}{c}\text { No. of } \\
\text { personnel }\end{array}$ & Percentage & Remarks \\
\hline $\begin{array}{c}\text { Therapeutic } \\
\text { duplication }\end{array}$ & 45 & 14.90 & Over look \\
$\begin{array}{c}\text { Drug use without } \\
\text { indication }\end{array}$ & 22 & 7.28 & Over look \\
$\begin{array}{c}\text { Contraindicated } \\
\text { drugs }\end{array}$ & 9 & 2.98 & Over look \\
$\begin{array}{c}\text { Prescription error } \\
\text { Potential D-D } \\
\text { interactions }\end{array}$ & 58 & 19.2 & Over look \\
$\begin{array}{c}\text { Potential ADRs } \\
\text { None }\end{array}$ & 13 & 1.655 & Over look \\
\hline
\end{tabular}

Question 19 is about any reported cases of ADRs by the patient to the pharmacist, and the results obtained are as follows:

\begin{tabular}{ccc}
\hline Reported cases of ADRs & No. of personnel & Percentage \\
\hline Yes & 104 & 34.43 \\
No & 198 & 65.56 \\
\hline
\end{tabular}

Question 20 is about the response of the pharmacist toward reported ADRs in question 20, and the results obtained are as follows:

\begin{tabular}{ccc}
\hline Response & No. of personnel & Percentage \\
\hline Self-advice & 30 & 28.84 \\
$\begin{array}{c}\text { Advised to refer to } \\
\text { physician }\end{array}$ & 74 & 71.15 \\
\hline
\end{tabular}

Question 21 is about whether the pharmacist is referring back to physician after finding an ADR: No pharmacist is referring back to the physician

Question 22 is about the pharmacist response when finds out a severe D-D interaction while dispensing, and the results obtained are as follows: Majority of pharmacists are unaware of D-D interaction

Question 23 is about opinion of pharmacist that his/ her profession is confined to dispensing and patient counseling, and the results obtained are as follows:

\begin{tabular}{ccc}
\hline Opinion of pharmacist & No. of personnel & Percentage \\
\hline Yes & 262 & 86.75 \\
No & 40 & 13.24 \\
\hline
\end{tabular}

Question 24 is about time taken for a pharmacist to do patient counselling whose opinion was yes for question 23 , and the results obtained are as follows:

\begin{tabular}{cc}
\hline Parameter & Value \\
\hline No. of personnel & 302 \\
Minimum time taken for patient counseling & 0 \\
Maximum time taken for patient counseling & 20 \\
Mean & 6.9040 \\
Median & 7.500 \\
Standard deviation & 3.0392 \\
Variance & 9.2366 \\
\hline
\end{tabular}

Question 25 is about other activities pharmacist would like to participate whose opinion was no for question 23, and the results obtained are as follows:

\begin{tabular}{ccc}
\hline Activities & No. of personnel & Percentage \\
\hline Safety analysis & 1 & 2.5 \\
Prescribing & 2 & 5 \\
OTC prescribing & 1 & 2.5 \\
Awareness programs & 36 & 90 \\
\hline
\end{tabular}

Question 26 is about best method for presenting drug use instructions and the results obtained are as follows:

\begin{tabular}{ccc}
\hline Method & $\begin{array}{c}\text { No. of } \\
\text { personnel }\end{array}$ & Percentage \\
\hline Oral & 171 & 56.62 \\
Written & 42 & 13.90 \\
Leaflets & 1 & 0.33 \\
Pictograms & 1 & 0.33 \\
Oral + written & 78 & 25.82 \\
Oral + leaflets & 1 & 0.33 \\
Oral+ pictograms & 4 & 1.32 \\
Oral + written +leaflet & 1 & 0.33 \\
Oral + written+ leaflet + & 1 & 0.33 \\
pictogram & 2 & 0.66 \\
Not interested & &
\end{tabular}

Question 27 is about does pharmacists warn the patient on potential ADRs or D-D interactions and the results obtained are as follows:

\begin{tabular}{ccc}
\hline & No. of personnel & Percentage \\
\hline Yes & 221 & 73.17 \\
No & 81 & 26.82 \\
\hline
\end{tabular}

Indian Journal of Pharmacy Practice, Vol 11, Issue 1, Jan-Mar, 2018 


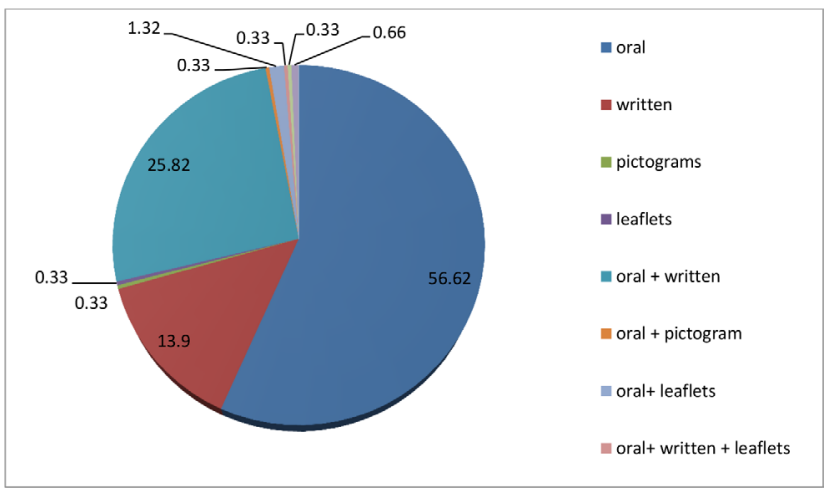

Figure 7: Methods followed by pharmacists for giving drug use instructions to patients.

Question 28 is about whether the pharmacist counsel the patient regarding life style modifications and the results obtained are as follows:

\begin{tabular}{ccc}
\hline Counsel & No. of personnel & Percentage \\
\hline Yes & 214 & 70.86 \\
No & 88 & 29.13 \\
\hline
\end{tabular}

Question 29 is about whether the pharmacist enquire female patients if they are pregnant or lactating, and the results obtained are as follows:

\begin{tabular}{ccc}
\hline & No. of personnel & percentage \\
\hline Yes & 262 & 86.75 \\
No & 40 & 13.2 \\
\hline
\end{tabular}

Question 30 is about, whether the pharmacist enquire the patient regarding drug allergy and the results obtained are as follows:

\begin{tabular}{ccc}
\hline & No. of personnel & percentage \\
\hline Yes & 214 & 70.86 \\
No & 88 & 29.13 \\
\hline
\end{tabular}

Question 31 is about, how many times the pharmacist confers the drug information text books or software in a week and the results obtained are as follows:

\begin{tabular}{ccc}
\hline Confer drug information & No. of personnel & Percentage \\
\hline Once in a week & 128 & 42.38 \\
Twice in a week & 25 & 8.27 \\
Once in a day & 10 & 3.31 \\
Once in a month & 1 & 0.33 \\
rare & 46 & 15.23 \\
none & 92 & 30.46 \\
\hline
\end{tabular}

Question 32 is about,from which sources does the pharmacist confer the drug information and the results obtained are as follows: Majority of the pharmacists response is that they confer drug information from CIMS, DRUG TODAY, INTERNET.

Question 33 is about, does the pharmacist can diagonise the disease based on patient complaints and the results obtained are as follows:

\begin{tabular}{ccc}
\hline Diagonise & No. of personnel & Percentage \\
\hline Yes & 198 & 65.56 \\
No & 104 & 34.33 \\
\hline
\end{tabular}

Question 34 is about, whether the pharmacist counsel the patient regarding the route of administration while dispensing a drug and the results obtained are as follows:

\begin{tabular}{ccc}
\hline Counsel & No. of personnel & Percentage \\
\hline Yes & 288 & 95.36 \\
No & 14 & 4.63 \\
\hline
\end{tabular}

Question 35 is about, does the pharmacy contain antidotes and the results obtained are as follows:

\begin{tabular}{ccc}
\hline Maintain Antidotes & No. of personnel & Percentage \\
\hline Yes & 74 & 24.50 \\
No & 228 & 75.49 \\
\hline
\end{tabular}

Question 36 is about does the pharmacy contain anti venom and anti-serum, and the results obtained are as follows:

\begin{tabular}{ccc}
\hline $\begin{array}{c}\text { Maintain antivenoum } \\
\text { and anti serum }\end{array}$ & No. of personnel & Percentage \\
\hline Yes & 25 & 8.27 \\
No & 277 & 91.72 \\
\hline
\end{tabular}

Question 37 is about opinion of the pharmacists that which suits best to pharmacy and the results obtained are as follows:

\begin{tabular}{ccc}
\hline Opinion & No. of personnel & Percentage \\
\hline OTC & 66 & 21.85 \\
PRECRIPTION & 174 & 57.61 \\
OTC + PRESCRIPTION & 62 & 20.52 \\
\hline
\end{tabular}

Question 38 is about whether the pharmacist does follow up after dispensing and OTC drug and the results obtained are as follows:

\begin{tabular}{ccc}
\hline Follow up & No. of personnel & Percentage \\
\hline Yes & 247 & 81.78 \\
No & 55 & 18.21 \\
\hline
\end{tabular}

Question 39 is about how does the pharmacist handle expired medications and the results obtained are as follows: 


\begin{tabular}{ccc}
\hline $\begin{array}{c}\text { Handling of expired } \\
\text { medications }\end{array}$ & No. of personnel & Percentage \\
\hline Garbage & 12 & 3.97 \\
Recycling & 278 & 92.05 \\
Garbage + recycling & 12 & 3.97 \\
\hline
\end{tabular}

Question 40 is about whether the pharmacist maintain and provide first aid in emergency conditions and the results obtained are as follows:

\begin{tabular}{ccc}
\hline $\begin{array}{c}\text { Maintain and provide firs } \\
\text { aid }\end{array}$ & $\begin{array}{c}\text { No. of } \\
\text { personnel }\end{array}$ & Percentage \\
\hline Yes & 222 & 73.50 \\
No & 80 & 26.49 \\
\hline
\end{tabular}

Question 41 is about whether the pharmacist provide any preventive care on seasonal disease, and the results obtained are as follows:

\begin{tabular}{ccc}
\hline $\begin{array}{c}\text { Provide preventive } \\
\text { care }\end{array}$ & No. of personnel & Percentage \\
\hline Yes & 240 & 79.4 \\
No & 62 & 20.52 \\
\hline
\end{tabular}

Question 42 is about how many h does a pharmacist work per day, and the results obtained are as follows:

\begin{tabular}{cc}
\hline Parameter & Value \\
\hline No. of personnel & 302 \\
Minimum time spent in working & 16 \\
Maximum time spent in working & 8 \\
Mean & 1.2530 \\
Median & 9 \\
Standard deviation & 2.1329 \\
Variance & 4.5491 \\
\hline
\end{tabular}

Question 43 is about how does the pharmacist dispense the following drugs like zolfresh ,restyl, roxanol, valium and the results obtained are as follows:

\begin{tabular}{ccc}
\hline Type of dispensing & No. of personnel & Percentage \\
\hline As OTC & 242 & 80.25 \\
Strictly with prescription & 60 & 19.74 \\
\hline
\end{tabular}

Question 44 is about how does the pharmacist dispense the corex syrup, and the results obtained are as follows:

\begin{tabular}{ccc}
\hline Type of dispensing & No. of personnel & Percentage \\
\hline As OTC & 272 & 90.33 \\
Strictly with prescription & 30 & 9.27 \\
\hline
\end{tabular}

\section{DISCUSSION}

Good Pharmacy Practice (GPP) is the essence of pharmacy profession. Moreover, it expresses our covenant with the patient not only to do no harm but also to facilitate good therapeutic outcomes with medicines. GPP is the practice of pharmacy that responds to the needs of the people who use the pharmacists services to provide optimal evidence-based care. The GPP indicator studies have also been undertaken to increase awareness of the problem of inappropriate pharmacy practices by dispensing pharmacists. The survey questionnaire was designed and prepared based on GPP. However, the main limitation of the study was the poor response rate from community pharmacists and the response rate was found to be $60.4 \%$. The low participation rate in the study and failure to answer some questions (especially for the question identifying drug/ medical related problems) may be due to poor qualification, knowledge and practice.

The key findings of this study are:

\section{Regarding the qualification}

Pharmacists from diploma background are 29 (9.6\%), B.Pharma are $58(19.2 \%)$, M.Pharma are 23 (7.61\%), Pharm D are $1(0.33 \%), 10+2$ are $48(15.8 \%), 10$ th are 12 (3.97\%), degree (B.com, B.Sc) are 131 (43.3\%).

This clearly indicates that in India anyone with any level of education can work as Community Pharmacists. Even 10th class passed out persons are working as community pharmacists, who happens to be lay persons when compared to the guide lines framed by IPA 2002 or the level of education offered in pharmacy courses.

\section{Regarding training period}

The maximum training period spent by the pharmacist was 180 days and minimum number of days spent was 0 . Majority of the pharmacists had lack of training. This makes them incompetent for analysing medication related problems in a prescription, and also these pharmacists confine themselves only to dispensing activities without any professional responsibilities.

\section{Regarding experience}

In this survey we have found that about $50 \%$ of the pharmacist have experience of more than 2-3 years and remaining are of experience with days to months. Here an important point to be noted is that there are very few dispensing pharmacists with an experience of 40 years (4 persons) and were practicing long before the IPA guidelines came into existence. These persons appear to be competent enough while filling the questionnaires, where as $50 \%$ of the personnel have $2-3$ years of experience, and these personnel have been employed 
very recently and by highly reputed chain of pharmacy stores. 15 years have passed by since IPA guidelines came into existence and yet it seems nobody cares about them, even the authorities have a blind eye when it comes to licensing and inspecting the pharmacy stores.

\section{Regarding position at pharmacy}

As per our survey we have found about $24.17 \%$ of dispensing pharmacists are owners and the remaining $75.82 \%$ are employee pharmacist working at different community pharmacies. Coupled with inefficiency and compelled by the owners of the pharmacy stores, these dispensing pharmacists confine themselves to selling of drugs without any professional morals and responsibilities.

\section{Regarding appearance}

In our study we came to know that majority of pharmacists were not wearing apron i.e; $83.44 \%$ while dispensing drugs. We have received different excuses for not wearing an apron while dispensing: some have stated that aprons will be worn only by a chief pharmacist who has got a pharmacy education, some have stated high temperatures in the city as an excuse and so on.

Whatever may the excuse, it should be remembered that dispensing is a profession and the dispensing personnel should appear professional at all times.

\section{Regarding procurement}

As per our survey maximum pharmacist follow VED analysis i.e; $99.33 \%$ for procurement of drugs and very few members follow $\mathrm{ABC}$ analysis i.e; $0.66 \%$.

This clearly indicates that the profession of dispensing has been commercialised and the pharmacies are there for making quick bucks.

\section{Regarding arrangement of the drugs}

According to our survey majority of the community pharmacies, and dispensing pharmacists follow alphabetical arrangement i.e; $90.72 \%$ and a very few pharmacists follow company wise, therapeutic category, fast/slow moving arrangement, chronological arrangement.

\section{Regarding insulin storage}

In our survey we have found that majority of dispensing pharmacists (98.67\%) are aware of storage conditions of insulin.

Indian Journal of Pharmacy Practice, Vol 11, Issue 1, Jan-Mar, 2018

\section{Regarding cold chain storage process}

As per our survey we have found that about $86.09 \%$ of dispensing pharmacists follow cold chain storage process. And yet a great number of dispensing personnel need to be educated on cold chain process and its importance.

\section{Regarding safety evaluation}

In our survey we have found that about $93.37 \%$ of dispensing pharmacists are of opinion that it is their responsibility for safety evaluation of prescription. In our survey few pharmacists responded that they are no were concerned with prescription evaluation.

It is surprising to find that the dispensing pharmacists accept that it is their responsibility to evaluate the prescription for safety and medication problems, but no one is applying it practice.

\section{Regarding drug or medical related problems}

- In our survey majority of dispensing pharmacist opined that it is not necessary to intervene in a prescription and are also with the opinion that pharmacists are not

- eligible to make any intervention in the prescription.

- A few pharmacists of about 30\% identified drug related problems and no one referred back to the physician.

- Majority of dispensing pharmacist are unaware of D-D interaction, contraindication and ADRs

\section{Regarding the reporting of ADRs by the patient}

In our survey we have found about $34.43 \%$ of the pharmacist had reported cases of ADRs by the patient in which very few pharmacists $(28.84 \%$ ) advised the patient by their own, advising them either an avil or cetrizine, and the remaining pharmacists referred the patient to a physician. None of the dispensing pharmacists are consulting the physician on this issue to take to the notice of the physician.

\section{Regarding the pharmacist profession}

- Majority of the dispensing pharmacists $86.75 \%$ are with opinion that pharmacist Role is confined to dispensing and counseling regarding the frequency of drug administration.

- Remaining dispensing pharmacists $13.24 \%$ are with opinion that apart from dispensing and counselling they can also participate in awareness programs and safety analysis. 
- Majority of the dispensing pharmacists counsel the patient for $<5 \mathrm{~min}(46.35 \%)$ and $5-10 \mathrm{~min}(42.38 \%)$ due to lack of knowledge, time and interest.

\section{Best Method for presenting drug use instructions to the patient}

Majority of the dispensing pharmacist's response was oral method $56.62 \%$

is the best method to provide instructions to the patient. But they have failed in explaining to illiterates.

Responsibility of the pharmacist while dispensing the drugs having potential ADRs and D-D interactions

- Majority of dispensing pharmacists are aware of only few potential ADRs and D-D interaction of drugs and felt responsible in warning patients about their use.

- Majority of dispensing pharmacists are unaware of CNS drugs and their potential ADRs.

\section{Regarding lifestyle modification}

In our survey about $70 \%$ of dispensing pharmacists counseling on life style modification for specific diseases like diabetes mellitus by recommending their products and are unaware of other diseases.

\section{Regarding the precautions while dispensing}

- About $70 \%$ of the dispensing pharmacists enquire regarding pregnancy and lactating condition while dispensing an OTC drug to a female patient.

- About $86 \%$ of the dispensing pharmacists enquire regarding the drug allergies while dispensing the OTC drugs to the patient.

\section{Upgradation of knowledge}

- About $53 \%$ of dispensing pharmacists confer drug information text books or softwares to upgrade knowledge regarding the brands and composition but not for its safety profile.

- About $15 \%$ of dispensing pharmacists rarely refer books or softwares.

- About 30\% dispensing pharmacists doesn't refer any books or software's due to lack of interest.

\section{Knowledge of dispensing pharmacists in diagnosing a} disease

About $63 \%$ of dispensing pharmacists are able to diagnose every common and seasonal disease based on patient complaints. But here they are lacking the concept of rational use of medicines, because we have received answers that they have been advising either azithromycin or amoxicillin and potassium clavulanate for viral symptoms and ofloxacin and orindazole combination for seasonal diarrhea.

\section{Regarding route of administration}

About $95 \%$ of dispensing pharmacists are providing instruction regarding route of administration.

\section{Maintenance of antidotes, anti-venom and anti-serum}

Majority of the pharmacist doesn't procure and maintain anti-venom, anti-serum and antidotes in pharmacies. Only activated charcoal is being maintained in these pharmacies and also almost all the pharmacies are following VED method of procurement, antivenom or antisera are not being maintained and also majority have responded that they will procure the necessary antivenom or antisera upon receiving an order. This clearly indicates that these personnel cannot understand the importance of stocking antivenom or antisera.

\section{Regarding the dispensing of the drugs}

- Majority of the dispensing pharmacists dispense OTC drugs i.e; $66 \%$ followed by prescription i.e; $57.6 \%$.

- After dispensing OTC, only about $24 \%$ of dispensing pharmacists are concerned with follow up and remaining are unaware of it.

\section{Handling of expired medication}

Majority of the dispensing pharmacists $92 \%$ return the expired medications for recycling.

\section{Maintenance of first aid kit}

About $73.5 \%$ of dispensing pharmacists maintain and provide first aid in emergency conditions.

\section{Regarding preventive care on seasonal diseases}

About $79.4 \%$ of the dispensing pharmacists are providing preventive care on seasonal disease's like viral infections.

\section{Work time spent by dispensing pharmacists in dispensing}

- According to our study maximum time spent by dispensing pharmacists in dispensing is of $16 \mathrm{~h}$ and its percentage is around 4.63 and minimum time spent by dispensing pharmacists in dispensing is $8 \mathrm{~h}$ which is around $7.61 \%$.

Indian Journal of Pharmacy Practice, Vol 11, Issue 1, Jan-Mar, 2018 
- Majority of dispensing pharmacists responded that they spend time in dispensing for about $9 \mathrm{~h}$ that is around $51.98 \%$.

\section{Dispensing patterns for specific drugs}

- Certain drugs require prescription in order to get dispensedby dispensing pharmacists such as narcotic drugs (eg: zolfresh, restyl, roxanol, valium).

- In our survey maximum dispensing pharmacists around $80.25 \%$ responded that Such drugs are dispensed strictly under prescription and in few cases, up to 3 doses are given without prescription.

- According to our survey maximum dispensing pharmacists, dispensing syrup Corex under OTC which was leading to abuse.

\section{CONCLUSION}

It's been more than two decades that the WHO-FIP jointly had framed GPP guidelines and it's been more than One and half decade that the IPA had framed GPP guidelines for the Indian Scenario and almost 9 years had passed by since the introduction of Pharm.D course in India, and yet there are lacunas in the system of education and vigilance from the authorities that have control over the medicines. In particular the community pharmacies are holding a deaf ear as far as the GPP guidelines are concerned.

Review of basic education in pharmacy is the first step to be looked into by the constitutional bodies. More education reforms are to be encouraged at the basic level of pharmacy education. Training Protocols that are followed by the Pharmacies are also to be reviewed and rectified.

With a huge population burden, and growing unemployed youth is a major problem that the country is currently facing. At this juncture, easy availability of manpower at a lower cost is also compromising the quality of services that are being offered at the community pharmacy Premises. The cheap manpower that is available due to unemployment are being diverted into dispensing activities without proper education or training and even without crisis management protocols. This severely is compromising the quality of Indian standards while the entire world is looking for India for medical services.

Also at the institutional level, the pharmacy students are to be thoroughly taught about the aspects that are covered in GPP guidelines at all levels of pharmacy education and practical aspects are also to be included into all levels of pharmacy education about GPP. Training should be made mandatory for all the personnel that wish to enter into the profession of dispensing.

The authorities should make it mandatory the presence of well-educated and well qualified and experienced persons as chief dispensing pharmacists and under whom pharmacy assistants may perform their duties. Prescription monitoring for Medication errors and potential Drug-Drug interactions and potential ADRs is also the responsibility of the dispensing pharmacists. Hence it is to be mandatory by the authorities that Prescription analysis is an integrated role of dispensing pharmacist which also have to be documented. If any medication errors are found in a prescription by the dispensing pharmacist, it should be immediately taken to the notice of the concerned Prescriber personally and should also be documented. The community pharmacists should be encouraged in this direction.

To conclude, more and more people are opting the profession of community pharmacist and this has increased since the past decade or so, and also the public is aware of what services it is obtaining at a community pharmacy and in this scenario, the authorities have to be extra vigilant right from education reforms, training and licensing. Also practicing pharmacists should be encouraged to update their knowledge by attending continuous education programmes. The morals and responsibilities of community pharmacists should be continuously reminded to the pharmacists.

\section{ACKNOWLEDGEMENT}

We would like to express our gratitude to everyone who was instrumental in this study.

\section{CONFLICT OF INTEREST}

No conflict of interest is declared.

\section{ABBREVIATIONS USED}

GPP- Good Pharmacy Practice ; WHO-FIP- World Health Organistion, International Pharmaceutical Federation ; SOP- Standard Operating Procedure ; OTC- Over The Counter ; IPA- Indian Pharmaceutical Association ; KAP- Knowledge, Attitude, Practice ; D.Pharm- Diploma in Pharmacy ;B.Pharm- Bachelor Of Pharmacy; M.Pharm- Master Of Pharmacy ; Pharm.D- Doctor of Pharmacy ;D-D interaction- DrugDrug interaction; ADRs- Adverse Drug Reactions 
;CNS- Central Nervous System ; VED - Vital, Essential, Desirable ; ABC- In materials management, the ABC analysis (or Selective Inventory Control) is an inventory categorization technique. $\mathrm{ABC}$ analysis divides an inventory into three categories- "A items" with very tight control and accurate records, "B items" with less tightly controlled and good records, and " $\mathrm{C}$ items" with the simplest controls possible and minimal records. ; FDCs- Fixed Dose Combinations ; ANOVA- Analysis of Variance

\section{REFERENCES}

1. JOINT FIP/WHO GUIDELINES ON GOOD PHARMACY PRACTICE: STANDARDS FOR QUALITY OF PHARMACY SERVICES. C. 2010. Assessed on 13/8/2016. Available from: http://www.who.int/medicines/ services/expertcommittees/pharmprep/CLEAN-Rev2Final-GPP-StandardsQPharmacyServices-QAS10-352_Sept2010.pdf

2. GOOD PHARMACY PRACTICE (GPP) IN COMMUNITY AND HOSPITAL PHARMACY SETTINGS. World Health Organization. 1996. Available from: http://www.cspc.in/cspc/Good\%20Pharmacy\%20Practice (WHO).pdf
3. Annex 8 Joint FIP/WHO guidelines on good pharmacy practice: standards for quality of pharmacy services. (c) World Health Organization WHO Technical Report Series, No. 961. 2011;(961)310-23. Available from: http://apps.who.int/ medicinedocs/documents/s18652en/s18652en.pdf

4. Working document. Joint FIP/WHO Guidelines on Good Pharmacy Practice: Standards for quality of pharmacy Services. c WHO. 2011;(961):310-23. Assessed on 13-8-2016. Available from: http://www.cpc-j.org/contents/ c12/20100605GPP.pdf

5. Good Pharmacy Practice (GPP) in community and hospital pharmacy settings. WHO 1996. WHO/PHJARM/DAP/96.1. c WHO. 1996. Assessed on 1308-2016. Available from: http://www.cspc.in/cspc/Good\%20Pharmacy\%20 Practice (WHO).pdf

6. Wiedenmayer K, Rob S. Summers, et al. Developing Pharmacy Practice: A focus on Patient care. Hand Book 2006 ed. WHO and FIP. 2006. Available from: http://apps.who.int/iris/bitstream/10665/69833/1/WHO_PSM_PAR_2006.5_ eng.pdf

7. Good Pharmacy Practice Guidelines : Guidelines For Delivery Of Pharmaceutical Services And Care In Community Pharmacy Settings In India. Indian Pharmaceutical Association. March. 2002. Assessed on 13-08-2016. Available from: http://www.ipapharma.org/html/GPP_Guidelines_IPA2002.pdf

8. Draugalis JR, Coons SJ and Plaza CM. Best practices for survey research reports: a synopsis for authors and reviewers. Am J Pharm Ed. 2008;72(1):1-6. doi: 10.5688/aj720111 